\title{
7
}

\section{DNA Methylation in Development}

\author{
Xin Pan, Roger Smith and Tamas Zakar \\ Mothers and Babies Research Centre, Hunter Medical Research Institute, \\ University of Newcastle, Newcastle, NSW, \\ Australia
}

\section{Introduction}

Early embryonic development is a very precise and complicated process. When a sperm meets an egg, a series of well-orchestrated changes take place, which end up with distinct types of cells that make up an organism. Cells start from a pluripotent state and differentiate without changes in DNA sequence. A differentiated cell shares the same DNA sequence with the zygote from which it is descended (mammalian B and T cells being an exception). The diverse functions of different cells are due to tissue-specific patterns of gene expression, which are established during development; once the fates of the cells are decided, they will be maintained faithfully through cell divisions. Hence it is reasonable to assert that development is, by definition, an epigenetic process (Reik, 2007). The specific gene expression programs in differentiated cells are regulated by a more flexible system, which dynamically switches on and off the genes for maintaining homeostasis or responding to environmental changes.

Epigenetics is defined as "the study of heritable changes in genome function that occur without alterations to the DNA sequence" (Probst, et al., 2009). Epigenetics has been suggested as the key regulatory system in early development. Mechanistically, epigenetic regulation involves the covalent modification of chromatin components such as DNA methylation and histone modifications (acetylation, methylation and phosphorylation are the best characterized). Short and long non-coding RNAs are also part of the epigenetic regulatory system because of their role in targeting the chromatin modifications within the genome (Hawkins \& Morris, 2008; Morris, 2009a). DNA methylation at the cytosine residue of CpG dinucleotides is the most studied epigenetic modification in mammals. Its effects on genome function underlie a number of physiological phenomena such as genomic imprinting and $\mathrm{X}$ chromosome inactivation, and it also contributes to the genesis of human cancers and to aging. CpG methylation was the only known chemical modification of mammalian genomic DNA with an epigenetic role before the discovery of 5hydroxymethylcytosine that will be discussed later (Haluskova, 2010; Ohgane, et al., 2008). CpG methylation is stable, heritable and reversible, which fulfils the requirement for a dynamic regulation system for development.

DNA methylation is most vulnerable to the environment during early development, because the genome methylation pattern is established during this stage and the DNA synthetic rate is very high in the early embryo. In mammals, proper DNA methylation is essential for 
normal development. Aberrant methylation patterns are involved in various developmental pathological phenomena and even diseases in adult life that are known under the rubric: the Developmental Origin of Health and Disease (DOHaD) (Waterland \& Michels, 2007).

In this chapter, we will discuss the biochemistry of DNA CpG methylation including the enzymes catalyzing the process and the controversial pathways of DNA demethylation. The dynamics of DNA methylation in early development will be covered as well as the role of methylation in cell-lineage determination, imprinting and the genesis of germ cells. We will also review the evidence supporting the importance of DNA methylation in DOHaD.

\section{The biochemical mechanism of DNA methylation}

DNA methylation occurs via covalent modification of cytosine by adding a methyl group to the carbon-5 of the pyrimidine ring mainly in a 5'-CG-3' dinucleotide pattern (CpG: C phosphodiester G). It is performed by the DNA methyltranferase (Dnmt) enzyme family. All identified Dnmts use S-Adenosylmethionine (SAM) as the methyl group $\left(\mathrm{CH}_{3}\right)$ donor. SAM, a biological sulfonium compound, is a major methyl donor involved in a number of essential reactions, including DNA, RNA and protein methylation (Lin, 2011).

The mechanism of DNA cytosine 5-methylation was analyzed for the prokaryotic Dnmt M.HhaI, which recognizes the specific sequence of 5'-GCGC-3' and methylates the first cytosine (J. C. Wu \& Santi, 1985, 1987). Prokaryotic and eukaryotic Dnmts share a number of conserved primary amino acid motifs that are believed to be important both structurally and functionally.

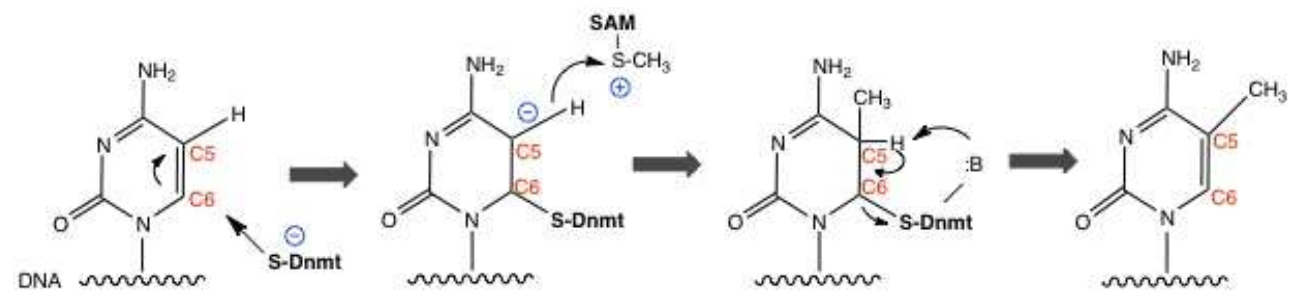

Fig. 1. Catalytic mechanism of cytosine methylation by Dnmt.

The Dnmt performs a nucleophilic attack on the C6, which leads to the formation of a covalent intermediate and activation of the C5. The activated C5 performs a nucleophilic attack on the methyl donor S-Adenosylmethionine (SAM) to acquire a methyl group from SAM. Following the methyl transfer, the C5 proton is eliminated and the intermediate is released, yielding the ultimate product: cytosine methylated on C5. Adapted from Kumar et al (1994).

The key features of the catalytic mechanism involve the nucleophilic attack on the carbon6 of the target cytosine by a conserved cysteine residue of the enzyme and formation of a covalent intermediate (Kumar, et al., 1994) (Fig 1). The process is induced by binding of the enzyme to DNA, which turns the target cytosine $180^{\circ}$ away from the DNA double helix and positions it in the active site with little disturbance to the rest of the DNA duplex. The details of this process, termed base flipping, are poorly understood (Gerasimaite, et al., 2011; Klimasauskas, et al., 1994; Matje, et al., 2011). The base flipping 
pulls the target base into closer contact with the enzyme, allowing for the accurate recognition of the extrahelical base and the subsequent chemical reactions. The catalytic loop of the enzyme, which contains six highly conserved residues, including the catalytic nucleophile cysteine residue, moves towards the DNA and stabilizes the extrahelical base for methylation (Hermann, Gowher, et al., 2004; Matje, et al., 2011). The nucleophilic attack on carbon- 6 is performed by the thiol group of the cysteine residue, whereas the carbon-5 is relatively unreactive. The positively charged sulfonium ion in SAM makes the methyl group that is bonded to the sulfur atom chemically reactive to nucleophilic attack (Hermann, Gowher, et al., 2004). The attack leads to the formation of a covalent intermediate between the enzyme and the carbon- 6 atom of the flipped out target cytosine, which results in activation of the carbon-5 atom. The activated carbon-5 performs a nucleophilic attack on SAM to acquire a methyl group from SAM. Following the methyl transfer, the carbon-5 proton is eliminated and the intermediate is released, yielding the ultimate product: cytosine methylated on carbon-5 (Hermann, Gowher, et al., 2004; Klimasauskas, et al., 1994; Kumar, et al., 1994; Yoo \& Medina-Franco, 2011).

\section{DNA methyltranferases (Dnmts)}

In mammals, the DNA methylation pattern is set up by three active members of the Dnmt family: Dnmt1, Dnmt3a and Dnmt3b. Dnmt3a and Dnmt3b are responsible for the de novo methylation that establishes the initial $\mathrm{CpG}$ methylation pattern during embryonic development, while Dnmt1 is required for maintenance of this pattern, copying the information to newly synthesized DNA during replication (Hermann, Goyal, et al., 2004). Although structurally similar to other Dnmts, the fourth member, Dnmt2, acts more as an RNA methyltransferase (Goll, et al., 2006). Dnmt3-Like protein (Dnmt3L) is a Dnmt-related protein that is catalytically inactive, but physically associates with Dnmt3a and Dnmt3b and modulates their catalytic activity (Hata, et al., 2002).

\subsection{Dnmt1}

Dnmt1 was the first discovered mammalian DNA methyltransferase (Gruenbaum, et al., 1982). It is highly conserved among eukaryotes. Dnmt1 is a large single polypeptide that comprises 1620 amino acid residues. It contains a large N-terminal domain and a smaller C-terminal part, which are connected by a linker of glycine-lysine repeats (Frauer, et al., 2011). The N-terminal domain comprises several motifs and is responsible for intracellular targeting and regulation of catalytic activity. The C-terminal part harbours all ten catalytic motifs that have been identified in bacterial Dnmts (Goll \& Bestor, 2005). However, studies have shown Dnmt1 exhibited no enzyme activity without the presence of its N-terminal domain (Fatemi, et al., 2001; Margot, et al., 2000; Zimmermann, et al., 1997). In agreement with this, direct interactions between the C-terminal and N-terminal parts have been observed and found necessary for Dnmt1 enzyme activity (Fatemi, et al., 2001; Margot, et al., 2003).

Dnmt1 is responsible predominantly for the maintenance of DNA methylation information through cell divisions. Targeted mutation of the Dnmt1 gene in mice was lethal with significantly reduced levels of DNA methylation (E. Li, et al., 1992). The preference of Dnmt1 for hemimethylated CpG sites that appear after DNA replication is the key property 
for this function. After DNA replication, methylated and unmethylated CpG sites are transformed into hemimethylated and unmethylated sites, respectively. Dnmt1 shows a 15to 50- fold preference for methylation at hemimethylated sites compared with unmethylated sites (Fatemi, et al., 2001; Pradhan, et al., 1999; Zucker, et al., 1985). Dnmt1 acts on hemimethylated sites to ensure maintenance of DNA methylation patterns from parental to daughter genomes, which also makes it a major target of current pharmaceutical interest. 5aza-cytidine, which is an inhibitor of Dnmt1, has been approved by US Food and Drug Administration (FDA) for the treatment of all subtypes of myelodysplatic syndromes (MDS) (Kaminskas, et al., 2005).

Dnmt1 was also found to have de novo methylation activity in mouse embryo lysates (Yoder, et al., 1997) and CpG island de novo methylation is related to Dnmt1 (Feltus, et al., 2003; Jair, et al., 2006). Additionally, Dnmt1 is required for maintenance of methylation in non-CpG DNA methylation (Grandjean, et al., 2007). Dnmt1 also interacts with a number of proteins, such as methyl-CpG binding proteins, histone deacetylases and histone methyltransferases, forming a complicated network regulating chromatin organization and gene expression (Kimura \& Shiota, 2003).

\subsection{Dnmt2}

Dnmt2 was identified through the analysis of expressed sequence tags (EST) databases during a search for de novo DNA methyltransferases in 1998 (Van den Wyngaert, et al., 1998; Yoder \& Bestor, 1998). Although the existence of all the consensus catalytic motifs strongly suggests DNA methyltranferase activity, no catalytic enzyme activity could be detected in initial assays. Dnmt2-deficient mouse embryonic stem cells were viable and no obvious DNA methylation changes were observed (Okano, et al., 1998b). The function of Dnmt2 remained enigmatic until a comparatively weak DNA methyltransferase activity was demonstrated both in vitro and in vivo (Hermann, et al., 2003; Kunert, et al., 2003; Liu, et al., 2003; Tang, et al., 2003).

The weak enzyme activity, however, is not sufficient explanation for the surprisingly extensive conservation of Dnmt2 among different species ranging from Schizosaccharomyces pombe to Homo sapiens, which indicates an important biological role. Moreover, the presence of Dnmt2 is not always accompanied by the presence of DNA methylation, which suggests Dnmt2 has additional functions (Schaefer \& Lyko, 2009). Studies have uncovered a robust transfer RNA (tRNA) methyltransferase activity of Dnmt2 through a DNA methyltransferase-like catalytic mechanism (Goll, et al., 2006; Jurkowski, et al., 2008). The functional significance of the dual DNA and RNA methyltransferase activity is still undiscovered. More work needs to be done to force the closed door of Dnmt2 open.

\subsection{Dnmt3 family}

The Dnmt3 family involves two active enzymes (Dnmt3a and Dnmt3b) and another Dnmtlike protein (Dnmt3L). Dnmt3a and Dnmt3b were identified in the human and the mouse through a search of EST databases using full-length bacterial type II cytosine-5 methyltransferase sequences. They share similar domain arrangements, including a variable region at the $\mathrm{N}$-terminal, which is involved in enzyme targeting, and a C-terminal catalytic domain (Chen, et al., 2004). 
Dnmt3a and Dnmt3b are highly expressed in undifferentiated embryonic stem (ES) cells. Though Dnmt3a expression can be readily detected in most adult tissues, Dnmt3b is expressed at very low levels in most tissues except testis, thyroid and bone marrow (Okano, et al., 1998a; Xie, et al., 1999). The methylation activities of Dnmt3a and Dnmt3b for unmethylated DNA and hemimethylated DNA are comparable (Okano, et al., 1998a). Inactivation of Dnmt3a and Dnmt3b in mouse ES cells impairs de novo methylation and causes postnatal and embryonic lethality respectively. Consequently, they were assigned to be responsible for the establishment of DNA methylation pattern during embryogenesis (Okano, et al., 1999).

Encoded by different genes, Dnmt3a and Dnmt3b are functionally overlapping. The embryonic defects in mouse ES cells deficient in both Dnmt3a and Dnmt3b are more severe than in single mutant mice (Okano, et al., 1999). The two enzymes, however, possesses different functions during embryogenesis. Dnmt3b is the major de novo DNA methyltransferase detected at embryonic day 4.5-7.0 (E4.5-7.0) in mouse embryonic cells, whereas Dnmt3a is significantly and ubiquitously detectable after E10.5 when Dnmt3b is below the detection level (Watanabe, et al., 2002). Mutation of Dnmt3b is identified to be responsible for a rare autosomal recessive disorder, which is termed as ICF syndrome, characterized by immunodeficiency, facial anomalies and centromere instability (Hansen, et al., 1999). Dnmt3b also participates in maintaining aberrant hypermethylation in colorectal cancer cells, acting cooperatively with Dnmt1 (Rhee, et al., 2002). Lately, high recurrence of Dnmt3a mutations has been reported in acute myeloid leukemia (Ley, et al., 2010; Shah \& Licht, 2011). In addition, certain CpG sites within the Fgf-1 gene locus have been proved to be selectively methylated by Dnmt3a in vivo but not by Dnmt3b (Oka, et al., 2006). The mechanism and significance of this activity are still undiscovered.

Although the third member of Dnmt3 family, Dnmt3L, shows a high degree of structural similarities of its N-terminal PHD-like zinc finger domain to Dnmt3a and Dnmt3b, it has been shown to have no catalytic activity. Key catalytic residues in C-terminal that are necessary for DNA methyltransferase activity are missing in Dnmt3L (Aapola, et al., 2000; Cheng \& Blumenthal, 2008). However, Dnmt3L was reported to play an important role in establishment of DNA methylation in maternally imprinted genes in mice (Hata, et al., 2002). Deletion of the Dnmt3L gene results in aberrant de novo methylation of dispersed repeated DNA sequences in male germ cells (Bourc'his \& Bestor, 2004). Besides, Dnmt3L has been shown to bind and colocalize with Dnmt3a and Dnmt3b in the nuclei of mammalian cells. It also stimulates de novo methylation by Dnmt3a in human cell lines (Chedin, et al., 2002; Hata, et al., 2002).

\section{CpG content and methylation pattern in the DNA of mammalian cells and relationship to gene activity}

In mammalian genomes, the abundance of $\mathrm{CpG}$ dinucleotides is less than expected on the basis of GC content. In human DNA, CPG incidence is only about $25 \%$ of what is expected considering the base composition (Saxonov, et al., 2006). Moreover, the CpG dinucleotides are unevenly distributed in the genome, forming clusters called $\mathrm{CpG}$ islands. According to the complete genomic sequence of human chromosomes 21 and 22, the CpG islands are characterized as DNA regions $>500$ bp with a GC content $>55 \%$ and observed 
CpG/expected CpG of 0.65 (Takai \& Jones, 2002). CpG islands occur at or near about $40 \%$ of mammalian promoters, and play crucial roles in the regulation of gene expression (Fatemi, et al., 2005). In accordance with this, bioinformatic evaluation showed a bimodal distribution of promoters segregating them into high CpG content and low CpG content classes (HCP and LCP, respectively) (Nagae, et al., 2011; Saxonov, et al., 2006). The two distributions overlap, and promoters in the overlapping region form a class of intermediate CpG content promoters (ICP, or “weak" CpG-promoters) (Weber, et al., 2007).

The majority of $\mathrm{CpG}$ sites are cytosine-methylated in genomic DNA with percentages between $60 \% \sim 90 \%$ depending on the source reports (Gruenbaum, et al., 1981; Razin, et al., 1984). The exceptions are CpG islands, where CpG sites are usually unmethylated. It follows that HCPs are usually undermethylated while LCPs are highly methylated at a level not different from the rest of genomic DNA. According to a genome-wide study (Weber, et al., 2007), $65 \%$ of established human promoters belong to the HCP class, but only $25 \%$ of the hypermethylated promoters are from this category. On the other hand, only $25 \%$ of promoters classify as LCP, but $42 \%$ of hypermethylated promoters belong to the LCP group. Notably, matching the promoter $\mathrm{CpG}$ density and methylation data with gene expression information in public databases has revealed that the undermethylated HCP-controlled genes often perform general "housekeeping" functions and are expressed in many tissues, while the highly methylated LCPs are frequently associated with tissue-specific functions and exhibit more restricted expression (Nagae, et al., 2011; Saxonov, et al., 2006; Weber, et al., 2007). Genome-scale analyses have also demonstrated that a small percentage of HCPs (3-4\%) is hypermethylated in somatic cells (Meissner, et al., 2008; Shen, et al., 2007; Weber, et al., 2007). More detailed examination of this subgroup has shown that it is enriched in germline-specific genes and in germline-derived cells, where the genes function, these HCPs are undermethylated. Collectively the above relationships between $\mathrm{CpG}$ density, methylation level and expression suggest that hypermethylation of HCPs is incompatible with gene activity and controls the tissue specific expression of a small group of genes in differentiated cells. The experimentally determined genome-wide relationship between $\mathrm{CpG}$ rich (HCP and ICP) promoter activity and methylation level supports this possibility (Weber, et al., 2007). The role of CpG methylation in controlling LCP-associated gene activity may be similar, but has been demonstrated only recently as discussed below.

Illingworth et al. (Illingworth, et al., 2008) devised a method to detect CpG islands experimentally and determine their methylation levels. They have found that about half of the islands overlap with annotated transcription start sites, the rest being intragenic and intergenic. Interestingly, these non-promoter $\mathrm{CpG}$ islands were methylated at a much higher frequency than annotated HCPs, and tissue-specific methylation was also more frequent. In another genome-wide study, methylation of intragenic $\mathrm{CpG}$ islands was found to correlate positively with the level of expression of the host gene (Straussman, et al., 2009). Therefore the possibility exists that many "non-promoter" CpG islands actually span unannotated transcription start sites and function as HCPs controlling the production of regulatory (suppressive) non-coding RNAs (Morris, 2009a, 2009b) in a tissue-specific and methylationsensitive fashion. Thus, some or most of the unmethylated HCPs may be regulated indirectly by methylation-sensitive $\mathrm{CpG}$ island promoters in a manner analogous to imprinted genes (Latos \& Barlow, 2009). 
Immunoprecipitation-based genome-wide analysis of promoters showed relatively high methylation levels of LCPs without significant relationship to promoter activity (Weber, et al., 2007). Since LCPs control many genes with tissue specific expression and function, this issue required further study. Nagae et al. used a sensitive beadarray technique (HumanMethylation27 BeadChip, Illumina) to determine the methylation level of 27587 individual CpG sites in 14475 promoters in 21 normal human tissue samples (Nagae, et al., 2011). As expected, HCPs were generally hypomethylated in all tissues. The CpG poor LCPs were methylated more extensively; however, the methylation level of individual LCPs varied widely between tissues. Gene ontology (GO) analysis showed that the hypomethylated, but not hypermethylated, LCPs in each tissue belonged to genes closely related to tissue specific functions. Furthermore, the expression of representative sets of tissue specific hypomethylated genes was increased in the corresponding tissue, while hypermethylation (relative to the average) had no relationship to expression. These methylation-sensitive LCPs were particularly enriched in transcription factor recognition motifs. Thus, LCPs are also regulated negatively by methylation, possibly by blocking transcription factor binding/activity at critical CpG sites. These results, together with the additional observation that many tissue-specific hypomethylated LCPs were fully methylated in embryonic stem cells and induced pluripotent cells (Nagae, et al., 2011), raise the possibility that terminal differentiation is associated with the demethylation of tissuespecific LCP-driven genes.

Genomic imprinting, which suppresses either the paternal or the maternal alleles of defined gene clusters, and $\mathrm{X}$ chromosome inactivation in females are the best characterised examples of gene silencing by CpG methylation (Heard, et al., 1997; Illingworth, et al., 2008; Latos \& Barlow, 2009). Both of these processes are integrated with development and will be discussed further below.

Finally, small, but detectable, non-CpG (notably CpA and CpT) methylation has been reported in mammalian genomes (Kouidou, et al., 2006; Ramsahoye, et al., 2000; White, et al., 2002). Bernard H. et al (Ramsahoye, et al., 2000) reported that $15 \sim 20 \%$ of total cytosine methylation in ESCs (embryonic stem cells) is at non-CpG sites, mostly at CpA and, to a less extent, at CpT. However, the establishment and maintenance of non-CpG methylation is unclear. It is reported that similar to CpG site methylation, non-CpG site methylation is also mediated by Dnmt3 and maintained by Dnmt1 (Grandjean, et al., 2007; Ramsahoye, et al., 2000; White, et al., 2002).

\section{Mechanisms of DNA methylation-mediated transcriptional repression}

As described in the previous section, DNA methylation is strongly associated with the suppression of gene expression. Two main mechanisms are involved in the repression and they are biologically relevant. First, DNA methylation has been shown to directly interfere with the binding of some transcription factors to the CpG sites. It is known that many factors bind $\mathrm{CpG}$-containing regions to stimulate gene expression, and a number of these consensus binding motifs (CRE, ETS, NRF-1, E-Box, AP2, etc, see ref. (Rozenberg, et al., 2008) and references therein) fail to bind or function if the CPG sites are methylated (Campanero, et al., 2000; Pierard, et al.; Sunahori, et al., 2009). 
The second mechanism involves recruitment of methyl-CpG-binding domain (MBD) proteins, which selectively recognize methylated $\mathrm{CpG}$ sites and silence associated genes by recruiting transcriptional corepressor complexes involving histone deacetylases (HDACs) and histone methyltransferases (P. A. Jones \& Laird, 1999; Munro, et al.; Prendergast \& Ziff, 1991). A family of MBD proteins has been identified that include MeCP2, MBD1, MBD2, MBD3 and MBD4 (Hendrich \& Bird, 1998). The MBD domains show homology among these proteins, whereas the transcription repression domains (TRD) identified in MeCP2, MBD1 and MBD2 are non-conserved.

$\mathrm{MeCP} 2$ is the founder of the MBD protein family, which represses gene expression by recruiting the corepressor mSin3A that interacts with HDAC1 (P. L. Jones, et al., 1998; Nan, et al., 1998). Mutation in the MeCP2 gene in the X-chromosome accounts for the vast majority of RTT (Rett) syndrome cases, which is a postnatal neurodevelopment disorder characterized by mental retardation, ataxia, hand stereotypes, seizures, and breathing irregularities (Amir, et al., 1999). MeCP2 represses gene expression by recruiting mSin3A, which interacts with HDAC1 (P. L. Jones, et al., 1998; Nan, et al., 1998). Mammalian MBD3 does not directly bind to CpG sites because of a mutation of the MBD (Saito \& Ishikawa, 2002). However, it is essential for embryogenesis, since targeted deletion of MBD3 results in mouse embryo lethality (Hendrich, et al., 2001). There is little evidence of MBD4 acting as a transcription repressor, instead, it is an important thymine DNA glycosylase involved in DNA repair (Hendrich, et al., 1999).

\section{5-hydroxymethylcytosine $(5 \mathrm{hmC})$, the sixth base of mammalian DNA}

Besides 5-methylcytosine $(5 \mathrm{mC})$, mammalian genomic DNA also contains 5hydroxymethylcytosine $(5 \mathrm{hmC})$, which is the oxidative modification of $5 \mathrm{mC}$ and is recognized as the sixth base of DNA. The first report of $5 \mathrm{hmC}$ in mammals was in 1972 (Penn, et al., 1972). Little attention, however, was attracted because of the lack of consistently reproducible data (Kothari \& Shankar, 1976). Two recent reports, however, brought $5 \mathrm{hmC}$ back into the limelight (Kriaucionis \& Heintz, 2009; Tahiliani, et al., 2009). Kriaucionis and Heintz detected $5 \mathrm{hmC}$ in mouse Purkinje cells and granule cells as $0.6 \%$ and $0.2 \%$ of total nucleotides, respectively. Tahiliani et al detected an even lower percentage of $5 \mathrm{hmC}$ in mouse ES cells, only $0.03 \%$ of all bases. After these discoveries, a number of methods were developed to distinguish $5 \mathrm{hmC}$ from $5 \mathrm{mC}$, since traditional bisulfite sequencing or methylation-sensitive restriction digestion do not differentiate between the two modified bases (Huang, et al., 2010; Jin, et al., 2010).

Munzel et al (Munzel, et al., 2010) have found that $5 \mathrm{hmC}$ is widely distributed in mouse brain. Relatively high levels of $5 \mathrm{hmC}$ were found in areas responsible for higher cognitive functions, such as in hippocampus and cortex. The level of $5 \mathrm{hmC}$ in mouse hippocampus increased by approximately $75 \%$ in 90 -day-old mice compared to in one-day-old mice, which was unrelated to oxidative DNA damage due to aging. Coincidentally, Song et al (Song, et al., 2010) reported an increase of $5 \mathrm{hmc}$ level from $0.1 \%$ of total nucleotides in postnatal day 7 to $0.4 \%$ in adult age in mouse cerebellum tissue. $5 \mathrm{hmC}$ is speculated to play an important role in central nervous system development.

The generation of $5 \mathrm{hmC}$ is based on the pre-existence of $5 \mathrm{mC}$ (Ficz, et al., 2011; Szwagierczak, et al., 2010; Williams, et al., 2011). The conversion of $5 \mathrm{mC}$ to $5 \mathrm{hmC}$ is 
achieved by the ten-eleven translocation (TET) enzyme family that has been identified in a homology search using the sequences of JBP1 and JPB2, which are responsible for hydroxylation and glucosylation of the 5-methyl group of thymine (Tahiliani, et al., 2009; $\mathrm{Yu}$, et al., 2007). Three members of TET family have been uncovered, TET1, TET2 and TET3. Lately, the TET protein has been reported to catalyse the generation of 5-carboxylcytosine $(5 \mathrm{caC})$ and 5-formylcytosine $(5 \mathrm{fC})$, which might be involved in the active demethylation of DNA (He, et al., 2011; Ito, et al., 2011).

The functional consequences of the $5 \mathrm{hmC}$ modification are still unclear. Like other modifications, it may alter chromatin organization by recruiting or excluding factors that influence transcription (S. C. Wu \& Zhang, 2010). Importantly, it is proposed to be involved in the enigmatic process of DNA demethylation. First, $5 \mathrm{hmC}$ cannot be recognised by Dnmt1. Therefore, it interferes with the Dnmt1-mediated maintenance of DNA methylation, which results in passive demethylation during replication (Valinluck \& Sowers, 2007). Second, it may be a key intermediate in the controversial process of active demethylation. We discuss this in detail in the section on DNA demethylation below. Additionally, it was reported that the MBD family, including MeCP2, MBD1, MBD2 and MBD4, have significantly reduced affinity for CpG sites that are hydroxymethylated (Jin, et al., 2010; Valinluck, et al., 2004). Given the repressive transcriptional role of MBD proteins and their interactions with histone modifying enzymes, the conversion from $5 \mathrm{mC}$ to $5 \mathrm{hmC}$ could reduce $\mathrm{MDB}$ activity at the affected sites and change epigenetic patterns to promote transcriptional activity.

\section{DNA demethylation in the zygote}

DNA methylation is a stable but not irreversible epigenetic mark. The reverse process, DNA demethylation, has been observed in specific contexts. Genome-wide DNA demethylation occurs after fertilization, when the existing DNA methylation pattern of the paternal and maternal genomes is erased and the epigenetic state of the early embryo is reset (Hajkova, et al., 2002; Mayer, et al., 2000).

The loss of DNA methylation is achieved in two distinct ways, passive demethylation and active demethylation. Passive demethylation occurs due to replication-dependent inhibition or absence of Dnmt1, which results in lack of DNA methylation in the newly synthesized DNA. Active demethylation refers to actively removing the methyl group, the methylated cytosine or the whole nucleotide; the mechanisms in mammals are still poorly understood and controversial.

Various mechanisms of active demethylation in mammals have been proposed, including direct enzymatic removal of the methyl group from $5 \mathrm{mC}$, nucleotide-replacement reaction and further modifications of $5 \mathrm{mC}$ followed by a base excision repair (BER) pathway.

Direct removal of the methyl group from $5 \mathrm{mC}$ seems to be the most direct way to achieve demethylation, however, a robust enzyme activity of a "demethylase" is needed to break the strong carbon-carbon bond. One of the MBD proteins, MBD2, is the first to be identified to serve as a DNA demethylase. MBD2 was shown in vitro to remove the methyl group and release in the form of methanol (Bhattacharya, et al., 1999). However, this mechanism was strongly contested because several groups failed to reproduce the enzyme activity in 
different genes (Boeke, et al., 2000; H. H. Ng, et al., 1999). Moreover, it has been revealed that MBD2-null mice still exhibit normal pattern of DNA methylation (Hendrich, et al., 2001), and the active demethylation of the paternal genome still occurs normally in zygote deficient in MBD2 (Santos, et al., 2002), which suggests that the major demethylation mechanisms do not involve MBD2.

The nucleotide-replacement reaction is commonly involved in substantial DNA repair following damage due to exposure to radiation or chemicals. The basic steps include dual incisions flanking the lesion, release of a $24 \sim 32$ nucleotide oligomer and replacement with new synthesized nucleotides followed by ligation (Sancar, et al., 2004). A DNA repair protein, growth arrest and DNA-damage-inducible 45a (Gadd45a), was reported to participate in active demethylation. Knockdown of Gadd45a leads to hypermethylation and gene silencing, whereas overexpression results in activation of loci-specific gene and global demethylation (Barreto, et al., 2007). Again, other studies failed to confirm the role of Gadd45a in active DNA demethylation, which raises doubts on this pathway (Engel, et al., 2009; Jin, et al., 2008).

The DNA glycosylase and base excision repair (BER) system mediated active demethylation is the main mechanism utilized by plants. The key steps involve a group of $5 \mathrm{mC}$ glycosylases (including ROS1, DME, DML2 and DML3) removing the methylated cytosine, followed by a BER pathway to fill in the gap with an unmethylated cytosine (J. K. Zhu, 2009). However, evidence supporting this mechanism in mammals seems less convincing due to the lack of $5 \mathrm{mC}$ glycosylase in mammalian cells. Although MBD4 and thymine DNA glycosylase (TDG), two confirmed $\mathrm{T} \bullet \mathrm{G}$ mismatch glycosylases, have been reported to have weak activity against $5 \mathrm{mC}$ : $\mathrm{G}$ in vitro, this activity is 30 40 fold lower compared to the T: G mismatch (B. Zhu, Zheng, Angliker, et al., 2000; B. Zhu, Zheng, Hess, et al., 2000). In addition, deletion of MBD4 does not affect the active demethylation of the paternal genome in zygotes, which challenges the possibility that MBD4 is the principal DNA demethylase operating after fertilization (Santos \& Dean, 2004).

It has also been proposed that active demethylation can be achieved by the deamination of $5 \mathrm{mC}$ to generate $\mathrm{T}$ followed by the BER pathway to replace the $\mathrm{T}$ with an unmethylated cytosine. The activation-induced deaminase (AID) and apolipoprotein B mRNA-editing catalytic polypeptides (Apobec) family are able to deaminate 5mC (Morgan, et al., 2004). Recent work has also shown that AID is necessary for promoter demethylation of the OCT4 and NANOG genes in the reprogramming of human somatic cells to pluripotent stem cells (Bhutani, et al., 2010). However, AID is active on single-stranded, but not on doublestranded DNA and its affinity to $5 \mathrm{mC}$ is 10 -fold lower than to unmethylated cytosine (Bransteitter, et al., 2003). Surprisingly, Dnmt3a and Dnmt3b have also been shown to possess $5 \mathrm{mC}$ deaminase activity in vitro, which may be involved in the CpG methylation/demethylation cycling observed at the pS2/TFF1 gene promoter after estrogen stimulation (Metivier, et al., 2008). More work needs to be done to uncover the mechanism and significance of these dual functions.

Recently, an oxidative-deamination-BER pathway (Fig.2) of active demethylation has been described with $5 \mathrm{hmC}$ as the key intermediate. The TET proteins have been shown to oxidize $5 \mathrm{mC}$ to generate $5 \mathrm{hmC}$ that is acted upon by the AID and Apobec family deaminases to generate $5 \mathrm{hmU}$ for subsequent processing by BER (Guo, et al., 2011). TDG exhibits robust 
glycosylase activity on the $5 \mathrm{hmU} \bullet \mathrm{G}$ mismatch to remove $5 \mathrm{hmU}$ and the gap is filled by an unmethylated cytosine. Both knockout and inactive point mutations of TDG result in mice embryo lethality and developmental defect (Cortellino, et al., 2011). In addition, it has been demonstrated that $5 \mathrm{mC}$ and $5 \mathrm{hmC}$ can be further modified to 5 -formylcytosine (5fC) and 5carboxylcytosine $(5 \mathrm{caC})$ by TET proteins. The existence of $5 \mathrm{fC}$ and $5 \mathrm{caC}$ has been identified in mice ES cells (Ito, et al., 2011). TDG is able to recognize and cleave $5 \mathrm{caC}$ and $5 \mathrm{fC}$ to initiate the BER pathway (He, et al., 2011; Maiti \& Drohat, 2011). It is also proposed that an unknown decarboxylase enzyme is involved in the conversion from $5 \mathrm{caC}$ to $\mathrm{C}$, without the participation of BER (Ito, et al., 2011).

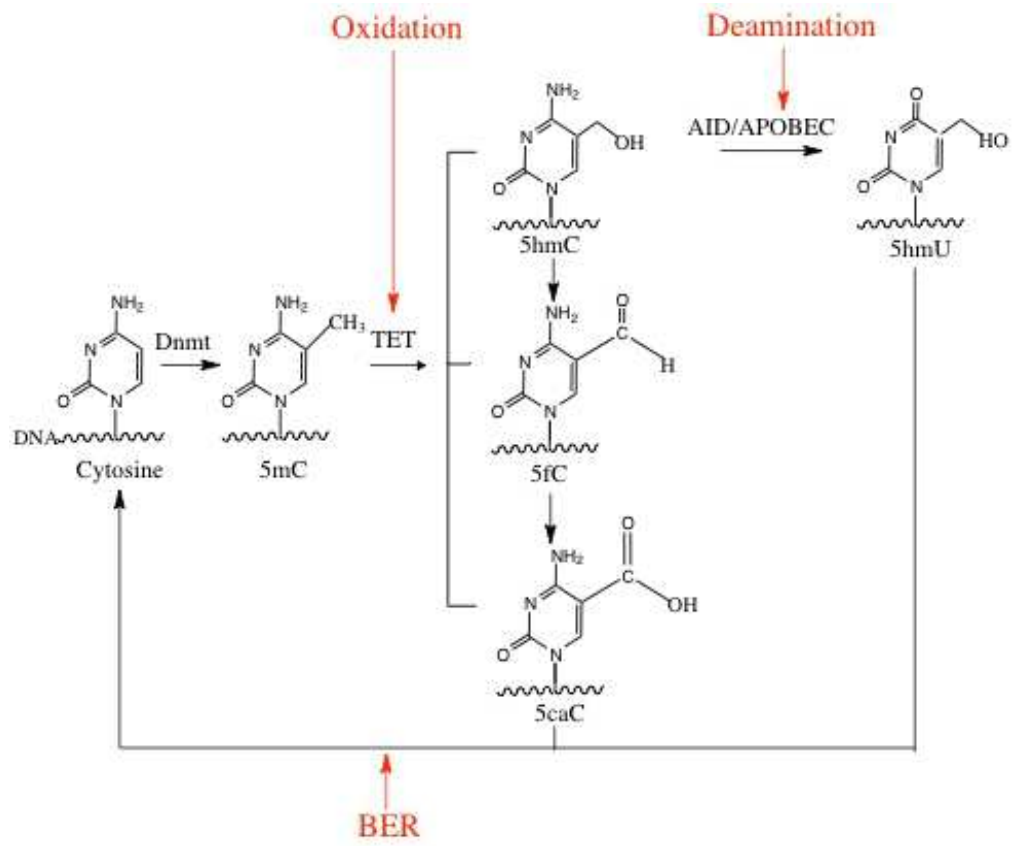

Fig. 2. Pathways of active DNA demethylation.

$5 \mathrm{mC}$ can be hydroxylated by TET to generate $5 \mathrm{hmC}$, which can be further oxidized to $5 \mathrm{fC}$ and $5 \mathrm{caC}$. Alternatively, $5 \mathrm{hmC}$ can be deaminased by AID and Apobec family members to generate $5 \mathrm{hmU}$. Base excision repair (BER) will be initiated by modified bases, eventually replacing them with cytosine.

\section{Dynamic of DNA methylation in development}

Extensive reprogramming of epigenomes occurs during early development, allowing cells to attain a totipotent developmental potential. Remodeling of DNA methylation patterns, including a genome-wide demethylation with imprinted genes as exceptions, is observed in mammalian zygotes, primordial germ cells and early embryos. This process is essential for erasure of the previous germ line DNA methylation pattern and establishment of new marks. 


\subsection{Asymmetric genome-wide demethylation}

The genomes of sperm and oocytes are organised differently. The genome of sperm is packaged with protamines, while oocytes are packaged with histones. At fertilization, a rapid exchange from protamine to histone occurs in the paternal genome. As early as a few hours after fertilization, a remarkable asymmetric DNA demethylation occurs in the two parental genomes, although they are exposed to the same oocyte cytoplasm. The paternal genome undergoes a genome-wide demethylation before the first cell division cycle, which is therefore considered active demethylation, while the maternal genome is protected from this reprogramming (Oswald, et al., 2000). Notably, some regions of the paternal genome are still resistant to demethylation, including imprinted genes.

Recent work from two laboratories has linked this loss of $5 \mathrm{mC}$ to its conversion to $5 \mathrm{hmC}$ (Iqbal, et al., 2011; Wossidlo, et al., 2011). Analysis of mouse, rabbit and bovine embryos showed a strong presence of $5 \mathrm{hmC}$ in the paternal pronucleus, while the amount of $5 \mathrm{mC}$ decreased. On the other hand, $5 \mathrm{hmC}$ in the maternal pronucleus was nearly undetectable, compared to the abundance of $5 \mathrm{mC}$. This suggests that $5 \mathrm{mC}$ in the paternal, but not in the maternal, pronuclei is converted to $5 \mathrm{hmC}$ possibly as part of the active demethylation pathway outlined above. The distribution differences of $5 \mathrm{hmC}$ in the two parental pronucleus were maintained towards the two-cell stage. It was also shown that TET3 contributed significantly to this conversion. Tet3 exhibits extremely high expression levels in oocytes and zygotes compared to the very low levels of TET1 and TET2. Levels of TET3 decrease dramatically at the two-cell stage, which stops the further increase of $5 \mathrm{hmC}$ levels. Knockdown of TET3 results in substantial reduction of $5 \mathrm{hmC}$ and a strong increase of $5 \mathrm{mC}$ in the paternal pronucleus. Consistent with the lack of active demethylation, the maternal pronucleus is inaccessible to this TET3-mediated conversion from $5 \mathrm{mC}$ to $5 \mathrm{hmC}$. Knockdown of TET3 has little effect on the $5 \mathrm{mC}$ signal in the maternal pronucleus.

An intriguing question is how the maternal pronucleus is protected from active demethylation. It has been proposed that the PGC7/Stella gene is important for this protection, since the maternal genome of the PGC7/Stella-null zygote undergoes significant demethylation (Coward, et al., 2009). It has also been reported that the absence of PGC7/Stella leads to the increase of $5 \mathrm{hmC}$ in the maternal pronucleus, which suggests PGC7/Stella as a protector of $5 \mathrm{mC}$ against oxidation (Wossidlo, et al., 2011). The mechanism of the protection, however, remains unclear. A further question is why the presence of PGC7/Stella does not protect the paternal pronucleus from demethylation. Structural differences may be the answer.

The maternal genome undergoes gradual passive demethylation during the several cell divisions leading towards blastocyst formation due to a lack of maintenance of methylation in the zygote. Imprinted genes are resistant to this process, as well as to the active demethylation in the paternal genome.

\subsection{Genomic imprinting}

Although extensive DNA methylation reprogramming occurs in early development, a number of genes are resistant to this change including imprinted genes. Gene imprinting is an enigmatic phenomenon that causes genes to be expressed in a parental-origin-specific way, wherein either the paternally or the maternally inherited allele is silenced. 
Approximately 60 imprinted genes have been identified in the human (R. K. Yuen, et al., 2011). Genomic imprinting plays a significant role in normal development through regulating embryo growth, placental function and neurobehavioral processes (McGrath \& Solter, 1984; Surani, et al., 1984). Abnormal expression of imprinted genes has been demonstrated to be associated with a few human diseases, including the Prader-Willi syndrome (PWS), the Angelman syndrome (AS), the Silver-Russell syndrome (SRS) and the Beckwith-Wiedemann syndrome (BWS) (Paulsen \& Ferguson-Smith, 2001).

DNA methylation is the key feature of imprinted gene clusters. The regions at imprinted loci marked by DNA methylation (DMRs) are methylated only on one allele. The product of one gene in an imprinted cluster is often a non-coding RNA, which regulates the expression of the other members of the cluster in cis. The DMRs established through the germ line often coincide with crucial imprinting control regions (ICRs), which if methylated, suppress the expression of the regulatory non-coding RNA. During development of primordial germ cells, DNA methylation is erased and then re-established in the process of oogenesis and spermatogenesis to generate gender specific germline imprinting patterns. Once established, the imprinted status will be stably maintained in all somatic lineages. Other DMRs acquire this methylation status after fertilization and are often tissue-specific (J. R. Mann, 2001). The mechanisms of the resistance of imprinted genes to epigenetic reprogramming post-fertilization are complex and still not fully characterised (see ref. (Weaver, et al., 2009)for review). A few factors have been suggested to be involved, including the DNMT1 isoforms DNMT1o and DNMT1s, MDB3 and PGC7/Stella, which also participates in the protection of the maternal genome from postfertilization active demethylation (Nakamura, et al., 2007). ZFP57, which is a KRAB zinc finger protein, has been demonstrated to be required for maintenance of maternal methylation imprints at the Snrpn imprinted region. It is also important for maintenance of genomic imprinting at multiple DMRs (X. Li, et al., 2008).

Dysregulation of imprinted genes are associated with a number of human syndromes that will be discussed in the following sections.

\subsection{DNA methylation in germ cell development}

After implantation of the blastocyst, a subset of pluripotent cells in the epiblast generate primordial germ cells (PGCs), the origin of both oocytes and spermatozoa, in responding to signals from extraembryonic ectoderm and visceral endoderm. Two critical transcription factors, B-lymphocyte maturation-induced protein1 (BLIMP1, also known as PR domain zinc finger protein1)) and PRDM14 are essential for specification of PGCs and suppression of somatic gene expression (Ohinata, et al., 2005; Saitou, 2009).

When the germ cell fate is established, the level of global DNA methylation is similar to that observed in surrounding epiblast cells (Seki, et al., 2005). The cells then gradually migrate to the genital ridge accompanied by significant reprogramming of epigenetic marks. A substantial reduction of genome-wide DNA methylation has been observed after specification of germ cells. However, it is not until arriving at genital ridge that DNA methylation including parental imprinting marks is extensively erased (Hajkova, et al., 2002). Due to the presence of Dnmt1 for most of the period, this widespread demethylation is considered to be active, replication-independent. BER pathway has been reported to be 
involved in the process. Interestingly, significant expression of TET1 gene has been detected in mouse PGCs, indicating a role of $5 \mathrm{hmC}$ as an intermediate in this active demethylation (Hajkova, et al., 2010).

In female mammals, one of the two copies of $X$ chromosomes is inactivated to balance the $X$ linked gene dosage between females and males. The process is termed $\mathrm{X}$ chromosome inactivation and is stably maintained in female somatic cells by the DNA methylation mark at the silenced genes. In female germ cell development, the inactivated $X$ chromosome is reactivated. This reactivation occurs during migration and gonadal colonization, which coincides with genome-wide DNA demethylation.

In the global demethylation of PGCs, parental imprinting marks are erased and reset in a gender specific fashion. In male germ cells, the new imprints are progressively established during late fetal development and are not completed until the mature sperm stage (J. Y. Li, et al., 2004). In contrast, the initiation of methylation imprints occurs postnatally during the oocyte growth phase (Lucifero, et al., 2004). The Dnmt3 family is responsible for the de novo methylation of imprinted DMRs. Knockout of Dnmt3a and Dnmt3b in mouse germ cell line revealed that although they are both involved, Dnmt3a plays the major role in establishment of imprinting with Dnmt3L as a critical co-factor (Kaneda, et al., 2004; Kato, et al., 2007).

\subsection{DNA methylation in cellular differentiation during development}

The evidence summarized above demonstrates that DNA (CpG) methylation is a critically important component of all aspects of cellular differentiation from fertilization to senescence. At the molecular level, CpG methylation of DNA results in gene silencing. Xchromosome inactivation and genomic imprinting are well characterised, specific examples of this phenomenon. In the developmental time line, the paternally and maternally inherited DNA methylation patterns are quickly erased in the zygote after fertilization by active and passive demethylation, respectively. DNA methylation levels in the genome reach a nadir at the morula stage (Abdalla, et al., 2009; Weaver, et al., 2009). In the subsequent phase of blastocyst formation, a primary differentiation event occurs, giving rise to two distinct cell lineages, the inner cell mass (ICM) and the trophectoderm. The ICM will generate the embryo proper as well as extraembryonic endoderm and mesoderm, while the trophectoderm will form the chorion and the placenta (Fleming, 1987). During blastocyst differentiation, a wave of de novo methylation is carried out by Dnmt3 family members, which leads to different methylation patterns between the ICM and trophectoderm. This occurs around the time of implantation. The main de novo Dnmt at the blastocyst stage, Dnmt $3 \mathrm{~b}$, has been specifically localized in the ICM of mouse blastocysts (Watanabe, et al., 2002). Thus the pluripotent stem cells of the ICM show much higher levels of DNA methylation compared to the trophectoderm; and this lineage-based methylation difference persists into the later stage of development, placenta and embryo proper (Santos, et al., 2002). The embryonic stem cells lose cell lineage restriction and differentiate into trophoblast cells after the deletion of Dnmt1, which implicates DNA methylation as the key factor to achieve cell lineage stability. At the gene expression level, the robust difference in methylation of a transcription factor encoding gene, Elf5, has been shown to be critical in cell lineage fate. It is hypermethylated and repressed in the embryonic cell lineage but hypomethylated and expressed in the trophoblast compartment (R. K. Ng, et al., 2008). 
The general genomic pattern of CpG methylation is established during ICM differentiation in the blastocyst at the time of implantation. Thus, CpG-rich promoters (HCPs and ICPs) remain unmethylated, probably due to the protective effect of cis-acting sequence motifs (Straussman, et al., 2009). On the other hand, CpG-poor promoters (LCPs), often controlling genes with tissue-specific expression are highly methylated possibly to prevent untimely expression in the pluripotent embryonic stem cells (ESCs) (Nagae, et al., 2011). The exceptions include the pluripotency and ESC-self renewal-associated genes, which often belong to the LCP class but are unmethylated in ESCs (e.g. Nanog, Pou5f1, Gdf3 (Straussman, et al., 2009)). Recent work suggests that the demethylation of Nanog is a TET1-dependent active process maintaining Nanog expression in mouse ESCs (Ito, et al., 2010). This example raises the possibility that other LCP class promoters also undergo targeted active demethylation in ESCs.

Differentiation of ESCs to various somatic cell types is also associated with changing DNA methylation of functionally relevant promoters. A small proportion of HCPs, controlling germline-specific genes, becomes methylated de novo in all cell types except for germlinederived cells (Shen, et al., 2007; Weber, et al., 2007), where they are expressed. Similarly, ESC-specific HCP-controlled genes are shut down in differentiated cells by de novo methylation of the promoter (Straussman, et al., 2009). CpG-island sequences at gene loci controlling development, such as OSR1, PAX6 and HOXC are frequently methylated in normal tissues; however, these methylations do not appear to correlate closely with gene expression levels (Illingworth, et al., 2008). The mechanisms that select these HCPs for methylation are unclear, but may involve other epigenetic marks such as histone modifications (Meissner, 2010). CpG-poor promoters (LCPs) undergo tissue-specific demethylation during differentiation, which correlates with the increased activity of functionally relevant genes (Nagae, et al., 2011). The mechanism of this gene and tissue selective process is unclear; it may involve the newly discovered TET-dependent active demethylation, or it may be passive demethylation driven by transcription factor binding to the promoter, which may prevent maintenance methylation after cell division.

The pattern of DNA methylation is considered stable after differentiation as long as cellular identity is maintained. Recent studies, however, have shown that the CpG methylation pattern changes during life. Christensen et al., (Christensen, et al., 2009) analysed 1413 CpG sites at 773 genes in 217 healthy individuals, and observed that $\mathrm{CpG}$ island methylation levels increased, while non-CpG island methylation levels decreased with age. Environmental factors, such as tobacco smoking, also affected CpG methylation levels in individuals. Yuen et al. (R. K. C. Yuen, et al., 2011) compared the methylation status of 1315 CpG loci in 752 genes from five somatic tissues between normal second trimester fetuses and adults. They found tissue-specific differentially methylated regions in 195 loci in the fetuses, but only $17 \%$ of these were maintained in adults. Further, the methylation status of about $10 \%$ of the examined sites changed more than $40 \%$ between the fetus and the adult. These data indicate the plasticity of the tissue-specific DNA methylation patterns and their susceptibility to environmental conditions.

\section{DNA methylation and human diseases}

Age and the environment have key importance in many disease processes; therefore it is not surprising that aberrant DNA methylation contributes to a variety of pathologies. Epigenetic 
changes have been firmly established as components of malignant transformation; however, this large area of investigation has been recently reviewed (Brait \& Sidransky, 2011) and is beyond the scope of this chapter (Esteller, 2011). In recent years, the relationship between adverse intrauterine conditions at early development and increased risk of post-natal diseases has been recognized.

Chronic diseases including cardiovascular disease, type 2 diabetes and obesity are associated with abnormal intrauterine growth and development (Hales \& Barker, 1992; Osmond, et al., 1993; Rich-Edwards, et al., 2005). This relationship has been termed as the Developmental Origins of Health and Disease (DOHaD). The hypothesis of $\mathrm{DOHaD}$ indicates a high degree of phenotypic plasticity during development. Epigenetic regulation have been suggested to be the most attractive mediator between transient environmental exposures and sustained changes at gene, cell or tissues levels. Especially, aberrant DNA methylation of key disease-associated genes has been suggested to be involved in $\mathrm{DOHaD}$.

\subsection{Role of maternal diet}

Maternal malnutrition is a comparatively well characterized factor influencing DNA methylation of genes in the context of DOHaD (See ref. (Burdge \& Lillycrop, 2010) for review). Further, several studies have reported that altered maternal intake of folate is linked to change of DNA methylation in the offspring (Kim, et al., 2009; Waterland, et al., 2006; Waterland \& Jirtle, 2003). Folate deficiency has been strongly associated with incomplete closure of the neural tube. Suppression of methylation cycles, which can be the consequence of insufficient maternal intake of folate, causes a high risk of neural tube defect in mice (Dunlevy, et al., 2006). Recently, it has been reported that reduced maternal folate status may contribute to the development of colorectal cancer in adult offspring (McKay, et al., 2011). Maternal folate depletion is associated with a locus-specific drop of DNA methylation in the Slc39a4 gene in fetal gut. The Slc39a4 gene has been shown to be hypomethylated in colorectal cancer. Thus the deficiency of folate in pregnancy might have consequence for colorectal cancer development if the altered methylation is sustained into adulthood.

Folate supplementation during pregnancy has been widely used to reduce the incidence of neural tube defects. It has been suspected, however, that folate may have adverse effects inducing allergic diseases such as asthma and eczema by altering the methylation status of DNA in the offspring (Dunstan, et al., 2011; Hollingsworth, et al., 2008).

Apart from nutrition, maternal behaviour (level of care, depression) has also been shown to alter the methylation of steroid receptor gene promoters in the offspring and influence steroid hormone sensitivity later in life (Champagne, et al., 2006; Oberlander, et al., 2008).

\subsection{Infection and inflammation}

Maternal infections such as urinary tract and periodontal infection have been correlated with pregnancy complications (reviewed in ref. (Conde-Agudelo, et al., 2008)). Treatment of periodontal disease during pregnancy was reported to reduce the rate of preterm birth and lower incidence of low birth weight (Polyzos, et al., 2009). The mechanisms underlying this relationship has been linked to abnormal DNA methylation patterns (Bobetsis, et al., 2007). 
Specifically, it has been shown in murine placenta tissues that maternal oral infection caused by $C$. rectus can induce hypermethylation in the promoter of imprinted insulin-like growth factor 2 (Igf2) gene. Deficiency of Igf2 gene expression leads to reduction of placental growth and restricted fetal growth (Constancia, et al., 2002). This suggests that DNA altered methylation (and expression) of key genes can contribute to infection-associated adverse pregnancy outcomes such as intrauterine growth restriction (IUGR).

Loss of DNA methylation in T cells has been shown in systemic lupus erythematosus (SLE), an autoimmune disease affecting multiple organs. A significant decrease of genomic DNA methylation with reduced Dnmt1 levels has been reported (Richardson, et al., 1990). Specific genes relevant to the SLE phenotype are also hypomethylated in T cells of SLE patients compared to their normal counterparts ( $\mathrm{Lu}$, et al., 2002; Oelke, et al., 2004). The DNA methylation inhibitor 5-aza-2'-deoxycytidine causes autoreactivity of T cells in vitro as well as an SLE-like disease in vivo, suggesting that T cell DNA hypomethylation is involved in the autoantibody response in SLE (Quddus, et al., 1993).

\subsection{Endometriosis}

Dysregulation of DNA methylation in several genes has been reported in endometriosis, a common gynecological condition affecting women of reproductive age. The promoter of progesterone receptor $\mathrm{B}$ (PR-B) has been shown to be hypermethylated in endometriosis, which may be responsible for PR-B down-regulation and the notable progesterone resistance ( $\mathrm{Y}$. Wu, et al., 2006). The promoter of estrogen receptor 2 (ESR2) is hypomethylated in endometriosis, which may result in the significantly increased level of estrogen receptor expression compared to the stromal cells in endometrium (Y. $\mathrm{Wu}$, et al., 2006).

\subsection{Disruptions of imprinting}

The human chromosome 11p15.5 harbours a cluster of imprinted genes including paternally expressed insulin-like growth factor 2 (IGF2) and maternally expressed H19 and KCNQ1 (KVLQT1) genes (Paulsen, et al., 1998). DNA methylation abnormalities at 11p15.5 can cause two distinct growth disorders, the Beckwith-Wiedemann (BWS) and the Silver-Russell (SRS) syndromes. BWS is characterized by fetal and postnatal overgrowth, macroglossia, neonatal hypoglycaemia and an increased incidence of childhood tumors. SRS is characterized by severe intrauterine and postnatal growth retardation, dysmorphic facial features, feeding difficulties, and body and limb asymmetry. DNA methylation defects account for approximately $60-70 \%$ of BWS and SRS patients (Demars, et al., 2011). Two imprinting control regions, ICR1 and ICR2, control the differential expression of imprinted genes at 11p15.5. Both the paternal and maternal alleles of ICR1 and ICR2 are methylated in normal cells. The DNA methylation defects at ICR1 is usually the hypermethylation of the maternal allele, leading to both BWS and SRS, whereas DNA methylation defects at ICR2 usually involve loss of maternal-allele-specific DNA methylation, which results in only BWS (Robertson, 2005).

Prader-Willi syndrome (PWS) and Angelman syndrome (AS) are two distinct neurogenetic disorders in which the same domain on chromosome 15 is affected. AS is caused by the loss of the maternally expressed gene, UBE3A, which is only imprinted in the brain. Loss of 
maternal DNA methylation or maternal ICR deletion is involved in the imprinting defects, which account for $\sim 5 \%$ of AS.

\subsection{ARTs and imprinting defects}

In the setting of infertility, the use of assisted reproductive technologies (ARTs) has been growing. Although the majorities of the children conceived with ARTs develop normally, recent studies have suggested a possible link between ARTs and genomic imprinting disorders. Cox et al. (2002) have reported that two children who were conceived by intracytoplasmic sperm injection (ICSI) develop AS and a third case has been reported by Orstavik et al. (2003). A loss of methylation on the maternal allele at SNRPN locus have been shown in all three children, while the paternal allele has normal methylation pattern, suggesting a relationship between AS and an ICSI associated imprinting defect. A few studies have also pointed to the association between the occurrence of BWS and in vitro fertilization (IVF) and ICSI. Hypomethylation of KCNQ1OT1 due to a chromosome 11p15.5 ICR2 defect as well as an abnormal methylation pattern of H19 have been observed in children conceived via ARTs (DeBaun, et al., 2003).

It has been proposed that in vitro manipulations of several steps involved in conception contribute to alteration of the normal imprinting processes. In current ARTs protocols, in vitro culturing of embryos is extended until the blastocyst stage before embryo transfer to allow high pregnancy rate and reduce the risk of multiple pregnancy. It has been demonstrated that culture of preimplantation embryos influences genomic imprinting marks (Khosla, et al., 2001; M. R. Mann, et al., 2004). ARTs also involve induced ovulation via hormonal stimulation and in vitro maturation of oocytes, which might interrupt the natural development of oocytes and the genomic imprinting marks of the maturing oocytes (Iliadou, et al., 2011).

The number of pathological conditions where aberrant DNA methylation is a contributor will likely increase as more refined technologies become available for the sensitive, accurate and high-throughput determination of $\mathrm{CpG}$ methylation at affordable prices. It is reasonable to expect that the complex mechanisms underlying $\mathrm{CpG}$ methylation, demethylation, methylation targeting and methylation protection will offer new therapeutic targets to alleviate the consequences of aberrant methylation in disease.

\section{References}

Aapola, U., Kawasaki, K., Scott, H. S., et al. (2000). Isolation and initial characterization of a novel zinc finger gene, DNMT3L, on 21q22.3, related to the cytosine-5methyltransferase 3 gene family. Genomics, 65(3), 293-298.

Abdalla, H., Yoshizawa, Y., \& Hochi, S. (2009). Active demethylation of paternal genome in mammalian zygotes. J Reprod Dev, 55(4), 356-360.

Amir, R. E., Van den Veyver, I. B., Wan, M., et al. (1999). Rett syndrome is caused by mutations in X-linked MECP2, encoding methyl-CpG-binding protein 2. Nat Genet, 23(2), 185-188.

Barreto, G., Schafer, A., Marhold, J., et al. (2007). Gadd45a promotes epigenetic gene activation by repair-mediated DNA demethylation. Nature, 445(7128), 671-675.

Bhattacharya, S. K., Ramchandani, S., Cervoni, N., \& Szyf, M. (1999). A mammalian protein with specific demethylase activity for mCpG DNA. Nature, 397(6720), 579-583. 
Bhutani, N., Brady, J. J., Damian, M., et al. (2010). Reprogramming towards pluripotency requires AID-dependent DNA demethylation. Nature, 463(7284), 1042-1047.

Bobetsis, Y. A., Barros, S. P., Lin, D. M., et al. (2007). Bacterial infection promotes DNA hypermethylation. J Dent Res, 86(2), 169-174.

Boeke, J., Ammerpohl, O., Kegel, S., Moehren, U., \& Renkawitz, R. (2000). The minimal repression domain of MBD2b overlaps with the methyl-CpG-binding domain and binds directly to Sin3A. J Biol Chem, 275(45), 34963-34967.

Bourc'his, D., \& Bestor, T. H. (2004). Meiotic catastrophe and retrotransposon reactivation in male germ cells lacking Dnmt3L. Nature, 431(7004), 96-99.

Brait, M., \& Sidransky, D. (2011). Cancer epigenetics: above and beyond. Toxicol Mech Methods, 21(4), 275-288.

Bransteitter, R., Pham, P., Scharff, M. D., \& Goodman, M. F. (2003). Activation-induced cytidine deaminase deaminates deoxycytidine on single-stranded DNA but requires the action of RNase. Proc Natl Acad Sci U S A, 100(7), 4102-4107.

Burdge, G. C., \& Lillycrop, K. A. (2010). Nutrition, epigenetics, and developmental plasticity: implications for understanding human disease. [Research Support, NonU.S. Gov't Review]. Annual review of nutrition, 30, 315-339.

Campanero, M. R., Armstrong, M. I., \& Flemington, E. K. (2000). CpG methylation as a mechanism for the regulation of E2F activity. Proc Natl Acad Sci U S A, 97(12), 64816486.

Champagne, F. A., Weaver, I. C., Diorio, J., et al. (2006). Maternal care associated with methylation of the estrogen receptor-alpha1b promoter and estrogen receptoralpha expression in the medial preoptic area of female offspring. Endocrinology, 147(6), 2909-2915.

Chedin, F., Lieber, M. R., \& Hsieh, C. L. (2002). The DNA methyltransferase-like protein DNMT3L stimulates de novo methylation by Dnmt3a. Proc Natl Acad Sci U $S$ A, 99(26), 16916-16921.

Chen, T., Tsujimoto, N., \& Li, E. (2004). The PWWP domain of Dnmt3a and Dnmt3b is required for directing DNA methylation to the major satellite repeats at pericentric heterochromatin. Mol Cell Biol, 24(20), 9048-9058.

Cheng, X., \& Blumenthal, R. M. (2008). Mammalian DNA methyltransferases: a structural perspective. Structure, 16(3), 341-350.

Christensen, B. C., Houseman, E. A., Marsit, C. J., et al. (2009). Aging and environmental exposures alter tissue-specific DNA methylation dependent upon CpG island context. [Research Support, N.I.H., Extramural Research Support, Non-U.S. Gov't]. PLoS genetics, 5(8), e1000602.

Conde-Agudelo, A., Villar, J., \& Lindheimer, M. (2008). Maternal infection and risk of preeclampsia: systematic review and metaanalysis. Am J Obstet Gynecol, 198(1), 722.

Constancia, M., Hemberger, M., Hughes, J., et al. (2002). Placental-specific IGF-II is a major modulator of placental and fetal growth. Nature, 417(6892), 945-948.

Cortellino, S., Xu, J., Sannai, M., et al. (2011). Thymine DNA glycosylase is essential for active DNA demethylation by linked deamination-base excision repair. Cell, 146(1), 67-79. 
Coward, W. R., Watts, K., Feghali-Bostwick, C. A., Knox, A., \& Pang, L. (2009). Defective histone acetylation is responsible for the diminished expression of cyclooxygenase 2 in idiopathic pulmonary fibrosis. Mol Cell Biol, 29(15), 4325-4339.

DeBaun, M. R., Niemitz, E. L., \& Feinberg, A. P. (2003). Association of in vitro fertilization with Beckwith-Wiedemann syndrome and epigenetic alterations of LIT1 and H19. Am J Hum Genet, 72(1), 156-160.

Demars, J., Rossignol, S., Netchine, I., et al. (2011). New insights into the pathogenesis of beckwith-wiedemann and silver-russell syndromes: Contribution of small copy number variations to 11p15 imprinting defects. Hum Mutat, 32(10), 1171-1182.

Dunlevy, L. P., Burren, K. A., Mills, K., et al. (2006). Integrity of the methylation cycle is essential for mammalian neural tube closure. Birth Defects Res A Clin Mol Teratol, 76(7), 544-552.

Dunstan, J. A., West, C., McCarthy, S., et al. (2011). The relationship between maternal folate status in pregnancy, cord blood folate levels, and allergic outcomes in early childhood. Allergy.

Engel, N., Tront, J. S., Erinle, T., et al. (2009). Conserved DNA methylation in Gadd45a(-/-) mice. Epigenetics, 4(2), 98-99.

Esteller, M. (2011). Cancer Epigenetics for the 21st Century. Genes \& Cancer, 2(6), 604-606.

Fatemi, M., Hermann, A., Pradhan, S., \& Jeltsch, A. (2001). The activity of the murine DNA methyltransferase Dnmt1 is controlled by interaction of the catalytic domain with the N-terminal part of the enzyme leading to an allosteric activation of the enzyme after binding to methylated DNA. J Mol Biol, 309(5), 1189-1199.

Fatemi, M., Pao, M. M., Jeong, S., et al. (2005). Footprinting of mammalian promoters: use of a CpG DNA methyltransferase revealing nucleosome positions at a single molecule level. Nucleic Acids Res, 33(20), e176.

Feltus, F. A., Lee, E. K., Costello, J. F., Plass, C., \& Vertino, P. M. (2003). Predicting aberrant CpG island methylation. Proc Natl Acad Sci U S A, 100(21), 12253-12258.

Ficz, G., Branco, M. R., Seisenberger, S., et al. (2011). Dynamic regulation of 5hydroxymethylcytosine in mouse ES cells and during differentiation. Nature, 473(7347), 398-402.

Fleming, T. P. (1987). A quantitative analysis of cell allocation to trophectoderm and inner cell mass in the mouse blastocyst. Dev Biol, 119(2), 520-531.

Frauer, C., Rottach, A., Meilinger, D., et al. (2011). Different binding properties and function of CXXC zinc finger domains in Dnmt1 and Tet1. PLoS One, 6(2), e16627.

Gerasimaite, R., Merkiene, E., \& Klimasauskas, S. (2011). Direct observation of cytosine flipping and covalent catalysis in a DNA methyltransferase. Nucleic Acids Res, 39(9), 3771-3780.

Goll, M. G., \& Bestor, T. H. (2005). Eukaryotic cytosine methyltransferases. Annu Rev Biochem, 74, 481-514.

Goll, M. G., Kirpekar, F., Maggert, K. A., et al. (2006). Methylation of tRNAAsp by the DNA methyltransferase homolog Dnmt2. Science, 311(5759), 395-398.

Grandjean, V., Yaman, R., Cuzin, F., \& Rassoulzadegan, M. (2007). Inheritance of an epigenetic mark: the CpG DNA methyltransferase 1 is required for de novo establishment of a complex pattern of non-CpG methylation. PLoS One, 2(11), e1136. 
Gruenbaum, Y., Cedar, H., \& Razin, A. (1982). Substrate and sequence specificity of a eukaryotic DNA methylase. Nature, 295(5850), 620-622.

Gruenbaum, Y., Stein, R., Cedar, H., \& Razin, A. (1981). Methylation of CpG sequences in eukaryotic DNA. FEBS Lett, 124(1), 67-71.

Guo, J. U., Su, Y., Zhong, C., Ming, G. L., \& Song, H. (2011). Hydroxylation of 5methylcytosine by TET1 promotes active DNA demethylation in the adult brain. Cell, 145(3), 423-434.

Hajkova, P., Erhardt, S., Lane, N., et al. (2002). Epigenetic reprogramming in mouse primordial germ cells. Mech Dev, 117(1-2), 15-23.

Hajkova, P., Jeffries, S. J., Lee, C., et al. (2010). Genome-wide reprogramming in the mouse germ line entails the base excision repair pathway. Science, 329(5987), 78-82.

Hales, C. N., \& Barker, D. J. (1992). Type 2 (non-insulin-dependent) diabetes mellitus: the thrifty phenotype hypothesis. Diabetologia, 35(7), 595-601.

Haluskova, J. (2010). Epigenetic studies in human diseases. Folia Biol (Praha), 56(3), 83-96.

Hansen, R. S., Wijmenga, C., Luo, P., et al. (1999). The DNMT3B DNA methyltransferase gene is mutated in the ICF immunodeficiency syndrome. Proc Natl Acad Sci U S A, 96(25), 14412-14417.

Hata, K., Okano, M., Lei, H., \& Li, E. (2002). Dnmt3L cooperates with the Dnmt3 family of de novo DNA methyltransferases to establish maternal imprints in mice. Development, 129(8), 1983-1993.

Hawkins, P. G., \& Morris, K. V. (2008). RNA and transcriptional modulation of gene expression. Cell Cycle, 7(5), 602-607.

He, Y. F., Li, B. Z., Li, Z., et al. (2011). Tet-Mediated Formation of 5-Carboxylcytosine and Its Excision by TDG in Mammalian DNA. Science.

Heard, E., Clerc, P., \& Avner, P. (1997). X-chromosome inactivation in mammals. [Review]. Annual Review of Genetics, 31, 571-610.

Hendrich, B., \& Bird, A. (1998). Identification and characterization of a family of mammalian methyl-CpG binding proteins. Mol Cell Biol, 18(11), 6538-6547.

Hendrich, B., Guy, J., Ramsahoye, B., Wilson, V. A., \& Bird, A. (2001). Closely related proteins MBD2 and MBD3 play distinctive but interacting roles in mouse development. Genes Dev, 15(6), 710-723.

Hendrich, B., Hardeland, U., Ng, H. H., Jiricny, J., \& Bird, A. (1999). The thymine glycosylase MBD4 can bind to the product of deamination at methylated CpG sites. Nature, 401(6750), 301-304.

Hermann, A., Gowher, H., \& Jeltsch, A. (2004). Biochemistry and biology of mammalian DNA methyltransferases. Cell Mol Life Sci, 61(19-20), 2571-2587.

Hermann, A., Goyal, R., \& Jeltsch, A. (2004). The Dnmt1 DNA-(cytosine-C5)methyltransferase methylates DNA processively with high preference for hemimethylated target sites. J Biol Chem, 279(46), 48350-48359.

Hermann, A., Schmitt, S., \& Jeltsch, A. (2003). The human Dnmt2 has residual DNA(cytosine-C5) methyltransferase activity. J Biol Chem, 278(34), 31717-31721.

Hollingsworth, J. W., Maruoka, S., Boon, K., et al. (2008). In utero supplementation with methyl donors enhances allergic airway disease in mice. J Clin Invest, 118(10), 34623469.

Huang, Y., Pastor, W. A., Shen, Y., et al. (2010). The behaviour of 5-hydroxymethylcytosine in bisulfite sequencing. PLoS One, 5(1), e8888. 
Iliadou, A. N., Janson, P. C., \& Cnattingius, S. (2011). Epigenetics and assisted reproductive technology. J Intern Med.

Illingworth, R., Kerr, A., Desousa, D., et al. (2008). A novel CpG island set identifies tissuespecific methylation at developmental gene loci. [Research Support, Non-U.S. Gov't]. PLoS Biol, 6(1), e22.

Iqbal, K., Jin, S. G., Pfeifer, G. P., \& Szabo, P. E. (2011). Reprogramming of the paternal genome upon fertilization involves genome-wide oxidation of 5-methylcytosine. Proc Natl Acad Sci U S A, 108(9), 3642-3647.

Ito, S., D'Alessio, A. C., Taranova, O. V., et al. (2010). Role of Tet proteins in 5mC to 5hmC conversion, ES-cell self-renewal and inner cell mass specification. Nature, 466(7310), 1129-1133.

Ito, S., Shen, L., Dai, Q., et al. (2011). Tet Proteins Can Convert 5-Methylcytosine to 5Formylcytosine and 5-Carboxylcytosine. Science.

Jair, K. W., Bachman, K. E., Suzuki, H., et al. (2006). De novo CpG island methylation in human cancer cells. Cancer Res, 66(2), 682-692.

Jin, S. G., Guo, C., \& Pfeifer, G. P. (2008). GADD45A does not promote DNA demethylation. PLoS Genet, 4(3), e1000013.

Jin, S. G., Kadam, S., \& Pfeifer, G. P. (2010). Examination of the specificity of DNA methylation profiling techniques towards 5-methylcytosine and 5hydroxymethylcytosine. Nucleic Acids Res, 38(11), e125.

Jones, P. A., \& Laird, P. W. (1999). Cancer epigenetics comes of age. Nat Genet, 21(2), 163-167.

Jones, P. L., Veenstra, G. J., Wade, P. A., et al. (1998). Methylated DNA and MeCP2 recruit histone deacetylase to repress transcription. Nat Genet, 19(2), 187-191.

Jurkowski, T. P., Meusburger, M., Phalke, S., et al. (2008). Human DNMT2 methylates tRNA(Asp) molecules using a DNA methyltransferase-like catalytic mechanism. RNA, 14(8), 1663-1670.

Kaminskas, E., Farrell, A. T., Wang, Y. C., Sridhara, R., \& Pazdur, R. (2005). FDA drug approval summary: azacitidine (5-azacytidine, Vidaza) for injectable suspension. Oncologist, 10(3), 176-182.

Kaneda, M., Okano, M., Hata, K., et al. (2004). Essential role for de novo DNA methyltransferase Dnmt3a in paternal and maternal imprinting. Nature, 429(6994), 900-903.

Kato, Y., Kaneda, M., Hata, K., et al. (2007). Role of the Dnmt3 family in de novo methylation of imprinted and repetitive sequences during male germ cell development in the mouse. Hum Mol Genet, 16(19), 2272-2280.

Khosla, S., Dean, W., Brown, D., Reik, W., \& Feil, R. (2001). Culture of preimplantation mouse embryos affects fetal development and the expression of imprinted genes. Biol Reprod, 64(3), 918-926.

Kim, J. M., Hong, K., Lee, J. H., Lee, S., \& Chang, N. (2009). Effect of folate deficiency on placental DNA methylation in hyperhomocysteinemic rats. J Nutr Biochem, 20(3), 172-176.

Kimura, H., \& Shiota, K. (2003). Methyl-CpG-binding protein, MeCP2, is a target molecule for maintenance DNA methyltransferase, Dnmt1. J Biol Chem, 278(7), 4806-4812.

Klimasauskas, S., Kumar, S., Roberts, R. J., \& Cheng, X. (1994). HhaI methyltransferase flips its target base out of the DNA helix. Cell, 76(2), 357-369. 
Kothari, R. M., \& Shankar, V. (1976). 5-Methylcytosine content in the vertebrate deoxyribonucleic acids: species specificity. J Mol Evol, 7(4), 325-329.

Kouidou, S., Malousi, A., \& Maglaveras, N. (2006). Methylation and repeats in silent and nonsense mutations of p53. Mutat Res, 599(1-2), 167-177.

Kriaucionis, S., \& Heintz, N. (2009). The nuclear DNA base 5-hydroxymethylcytosine is present in Purkinje neurons and the brain. Science, 324(5929), 929-930.

Kumar, S., Cheng, X., Klimasauskas, S., et al. (1994). The DNA (cytosine-5) methyltransferases. Nucleic Acids Res, 22(1), 1-10.

Kunert, N., Marhold, J., Stanke, J., Stach, D., \& Lyko, F. (2003). A Dnmt2-like protein mediates DNA methylation in Drosophila. Development, 130(21), 5083-5090.

Latos, P. A., \& Barlow, D. P. (2009). Regulation of imprinted expression by macro noncoding RNAs. [Research Support, Non-U.S. Gov't Review]. RNA biology, 6(2), 100106.

Ley, T. J., Ding, L., Walter, M. J., et al. (2010). DNMT3A mutations in acute myeloid leukemia. N Engl J Med, 363(25), 2424-2433.

Li, E., Bestor, T. H., \& Jaenisch, R. (1992). Targeted mutation of the DNA methyltransferase gene results in embryonic lethality. Cell, 69(6), 915-926.

Li, J. Y., Lees-Murdock, D. J., Xu, G. L., \& Walsh, C. P. (2004). Timing of establishment of paternal methylation imprints in the mouse. Genomics, 84(6), 952-960.

Li, X., Ito, M., Zhou, F., et al. (2008). A maternal-zygotic effect gene, Zfp57, maintains both maternal and paternal imprints. Dev Cell, 15(4), 547-557.

Lin, H. (2011). S-Adenosylmethionine-dependent alkylation reactions: When are radical reactions used? Bioorg Chem.

Liu, K., Wang, Y. F., Cantemir, C., \& Muller, M. T. (2003). Endogenous assays of DNA methyltransferases: Evidence for differential activities of DNMT1, DNMT2, and DNMT3 in mammalian cells in vivo. Mol Cell Biol, 23(8), 2709-2719.

Lu, Q., Kaplan, M., Ray, D., et al. (2002). Demethylation of ITGAL (CD11a) regulatory sequences in systemic lupus erythematosus. Arthritis Rheum, 46(5), 1282-1291.

Lucifero, D., Mann, M. R., Bartolomei, M. S., \& Trasler, J. M. (2004). Gene-specific timing and epigenetic memory in oocyte imprinting. Hum Mol Genet, 13(8), 839-849.

Maiti, A., \& Drohat, A. C. (2011). Thymine DNA glycosylase can rapidly excise 5formylcytosine and 5-carboxylcytosine: Potential implications for active demethylation of CpG sites. J Biol Chem.

Mann, J. R. (2001). Imprinting in the germ line. Stem Cells, 19(4), 287-294.

Mann, M. R., Lee, S. S., Doherty, A. S., et al. (2004). Selective loss of imprinting in the placenta following preimplantation development in culture. Development, 131(15), 3727-3735.

Margot, J. B., Aguirre-Arteta, A. M., Di Giacco, B. V., et al. (2000). Structure and function of the mouse DNA methyltransferase gene: Dnmt1 shows a tripartite structure. J Mol Biol, 297(2), 293-300.

Margot, J. B., Ehrenhofer-Murray, A. E., \& Leonhardt, H. (2003). Interactions within the mammalian DNA methyltransferase family. BMC Mol Biol, 4, 7.

Matje, D. M., Coughlin, D. F., Connolly, B. A., Dahlquist, F. W., \& Reich, N. O. (2011). Determinants of precatalytic conformational transitions in the DNA cytosine methyltransferase M.HhaI. Biochemistry, 50(9), 1465-1473. 
Mayer, W., Niveleau, A., Walter, J., Fundele, R., \& Haaf, T. (2000). Demethylation of the zygotic paternal genome. Nature, 403(6769), 501-502.

McGrath, J., \& Solter, D. (1984). Completion of mouse embryogenesis requires both the maternal and paternal genomes. Cell, 37(1), 179-183.

McKay, J. A., Wong, Y. K., Relton, C. L., Ford, D., \& Mathers, J. C. (2011). Maternal folate supply and sex influence gene-specific DNA methylation in the fetal gut. Mol Nutr Food Res.

Meissner, A. (2010). Epigenetic modifications in pluripotent and differentiated cells. Nat Biotech, 28(10), 1079-1088.

Meissner, A., Mikkelsen, T. S., Gu, H., et al. (2008). Genome-scale DNA methylation maps of pluripotent and differentiated cells. Nature.

Metivier, R., Gallais, R., Tiffoche, C., et al. (2008). Cyclical DNA methylation of a transcriptionally active promoter. Nature, 452(7183), 45-50.

Morgan, H. D., Dean, W., Coker, H. A., Reik, W., \& Petersen-Mahrt, S. K. (2004). Activationinduced cytidine deaminase deaminates 5-methylcytosine in DNA and is expressed in pluripotent tissues: implications for epigenetic reprogramming. J Biol Chem, 279(50), 52353-52360.

Morris, K. V. (2009a). Long antisense non-coding RNAs function to direct epigenetic complexes that regulate transcription in human cells. Epigenetics, 4(5), 296-301.

Morris, K. V. (2009b). RNA-Directed Transcriptional Gene Silencing and Activation in Human Cells. Oligonucleotides, 19(4), 299-306.

Munro, S. K., Farquhar, C. M., Mitchell, M. D., \& Ponnampalam, A. P. Epigenetic regulation of endometrium during the menstrual cycle. Mol Hum Reprod, 16(5), 297-310.

Munzel, M., Globisch, D., Bruckl, T., et al. (2010). Quantification of the sixth DNA base hydroxymethylcytosine in the brain. Angew Chem Int Ed Engl, 49(31), 5375-5377.

Nagae, G., Isagawa, T., Shiraki, N., et al. (2011). Tissue-specific demethylation in CpG-poor promoters during cellular differentiation. Hum Mol Genet, 20(14), 2710-2721.

Nakamura, T., Arai, Y., Umehara, H., et al. (2007). PGC7/Stella protects against DNA demethylation in early embryogenesis. Nat Cell Biol, 9(1), 64-71.

Nan, X., Ng, H. H., Johnson, C. A., et al. (1998). Transcriptional repression by the methylCpG-binding protein MeCP2 involves a histone deacetylase complex. Nature, 393(6683), 386-389.

Ng, H. H., Zhang, Y., Hendrich, B., et al. (1999). MBD2 is a transcriptional repressor belonging to the MeCP1 histone deacetylase complex. Nat Genet, 23(1), 58-61.

$\mathrm{Ng}$, R. K., Dean, W., Dawson, C., et al. (2008). Epigenetic restriction of embryonic cell lineage fate by methylation of Elf5. Nat Cell Biol, 10(11), 1280-1290.

Oberlander, T. F., Weinberg, J., Papsdorf, M., et al. (2008). Prenatal exposure to maternal depression, neonatal methylation of human glucocorticoid receptor gene (NR3C1) and infant cortisol stress responses. Epigenetics, 3(2), 97-106.

Oelke, K., Lu, Q., Richardson, D., et al. (2004). Overexpression of CD70 and overstimulation of IgG synthesis by lupus $\mathrm{T}$ cells and $\mathrm{T}$ cells treated with DNA methylation inhibitors. Arthritis Rheum, 50(6), 1850-1860.

Ohgane, J., Yagi, S., \& Shiota, K. (2008). Epigenetics: the DNA methylation profile of tissuedependent and differentially methylated regions in cells. Placenta, 29 Suppl A, S2935 . 
Ohinata, Y., Payer, B., O'Carroll, D., et al. (2005). Blimp1 is a critical determinant of the germ cell lineage in mice. Nature, 436(7048), 207-213.

Oka, M., Rodic, N., Graddy, J., Chang, L. J., \& Terada, N. (2006). CpG sites preferentially methylated by Dnmt3a in vivo. J Biol Chem, 281(15), 9901-9908.

Okano, M., Bell, D. W., Haber, D. A., \& Li, E. (1999). DNA methyltransferases Dnmt3a and Dnmt3b are essential for de novo methylation and mammalian development. Cell, 99(3), 247-257.

Okano, M., Xie, S., \& Li, E. (1998a). Cloning and characterization of a family of novel mammalian DNA (cytosine-5) methyltransferases. Nat Genet, 19(3), 219-220.

Okano, M., Xie, S., \& Li, E. (1998b). Dnmt2 is not required for de novo and maintenance methylation of viral DNA in embryonic stem cells. Nucleic Acids Res, 26(11), 25362540.

Osmond, C., Barker, D. J., Winter, P. D., Fall, C. H., \& Simmonds, S. J. (1993). Early growth and death from cardiovascular disease in women. BMJ, 307(6918), 1519-1524.

Oswald, J., Engemann, S., Lane, N., et al. (2000). Active demethylation of the paternal genome in the mouse zygote. Curr Biol, 10(8), 475-478.

Paulsen, M., Davies, K. R., Bowden, L. M., et al. (1998). Syntenic organization of the mouse distal chromosome 7 imprinting cluster and the Beckwith-Wiedemann syndrome region in chromosome 11p15.5. Hum Mol Genet, 7(7), 1149-1159.

Paulsen, M., \& Ferguson-Smith, A. C. (2001). DNA methylation in genomic imprinting, development, and disease. J Pathol, 195(1), 97-110.

Penn, N. W., Suwalski, R., O'Riley, C., Bojanowski, K., \& Yura, R. (1972). The presence of 5hydroxymethylcytosine in animal deoxyribonucleic acid. Biochem J, 126(4), 781-790.

Pierard, V., Guiguen, A., Colin, L., et al. DNA cytosine methylation in the bovine leukemia virus promoter is associated with latency in a lymphoma-derived B-cell line: potential involvement of direct inhibition of cAMP-responsive element (CRE)binding protein/CRE modulator/activation transcription factor binding. $J$ Biol Chem, 285(25), 19434-19449.

Polyzos, N. P., Polyzos, I. P., Mauri, D., et al. (2009). Effect of periodontal disease treatment during pregnancy on preterm birth incidence: a metaanalysis of randomized trials. Am J Obstet Gynecol, 200(3), 225-232.

Pradhan, S., Bacolla, A., Wells, R. D., \& Roberts, R. J. (1999). Recombinant human DNA (cytosine-5) methyltransferase. I. Expression, purification, and comparison of de novo and maintenance methylation. J Biol Chem, 274(46), 33002-33010.

Prendergast, G. C., \& Ziff, E. B. (1991). Methylation-sensitive sequence-specific DNA binding by the c-Myc basic region. Science, 251(4990), 186-189.

Probst, A. V., Dunleavy, E., \& Almouzni, G. (2009). Epigenetic inheritance during the cell cycle. Nat Rev Mol Cell Biol, 10(3), 192-206.

Quddus, J., Johnson, K. J., Gavalchin, J., et al. (1993). Treating activated CD4+ T cells with either of two distinct DNA methyltransferase inhibitors, 5-azacytidine or procainamide, is sufficient to cause a lupus-like disease in syngeneic mice. J Clin Invest, 92(1), 38-53.

Ramsahoye, B. H., Biniszkiewicz, D., Lyko, F., et al. (2000). Non-CpG methylation is prevalent in embryonic stem cells and may be mediated by DNA methyltransferase 3a. Proc Natl Acad Sci U S A, 97(10), 5237-5242. 
Razin, A., Webb, C., Szyf, M., et al. (1984). Variations in DNA methylation during mouse cell differentiation in vivo and in vitro. Proc Natl Acad Sci U S A, 81(8), 2275-2279.

Reik, W. (2007). Stability and flexibility of epigenetic gene regulation in mammalian development. Nature, 447(7143), 425-432.

Rhee, I., Bachman, K. E., Park, B. H., et al. (2002). DNMT1 and DNMT3b cooperate to silence genes in human cancer cells. Nature, 416(6880), 552-556.

Rich-Edwards, J. W., Kleinman, K., Michels, K. B., et al. (2005). Longitudinal study of birth weight and adult body mass index in predicting risk of coronary heart disease and stroke in women. BMJ, 330(7500), 1115.

Richardson, B., Scheinbart, L., Strahler, J., et al. (1990). Evidence for impaired T cell DNA methylation in systemic lupus erythematosus and rheumatoid arthritis. Arthritis Rheum, 33(11), 1665-1673.

Robertson, K. D. (2005). DNA methylation and human disease. Nat Rev Genet, 6(8), 597-610.

Rozenberg, J. M., Shlyakhtenko, A., Glass, K., et al. (2008). All and only CpG containing sequences are enriched in promoters abundantly bound by RNA polymerase II in multiple tissues. BMC Genomics, 9, 67.

Saito, M., \& Ishikawa, F. (2002). The mCpG-binding domain of human MBD3 does not bind to $\mathrm{mCpG}$ but interacts with NuRD/Mi2 components HDAC1 and MTA2. J Biol Chem, 277(38), 35434-35439.

Saitou, M. (2009). Germ cell specification in mice. Curr Opin Genet Dev, 19(4), 386-395.

Sancar, A., Lindsey-Boltz, L. A., Unsal-Kacmaz, K., \& Linn, S. (2004). Molecular mechanisms of mammalian DNA repair and the DNA damage checkpoints. Annu Rev Biochem, 73, 39-85.

Santos, F., \& Dean, W. (2004). Epigenetic reprogramming during early development in mammals. Reproduction, 127(6), 643-651.

Santos, F., Hendrich, B., Reik, W., \& Dean, W. (2002). Dynamic reprogramming of DNA methylation in the early mouse embryo. Dev Biol, 241(1), 172-182.

Saxonov, S., Berg, P., \& Brutlag, D. L. (2006). A genome-wide analysis of CpG dinucleotides in the human genome distinguishes two distinct classes of promoters. Proc Natl Acad Sci U S A, 103(5), 1412-1417.

Schaefer, M., \& Lyko, F. (2009). Solving the Dnmt2 enigma. Chromosoma, 119(1), 35-40.

Seki, Y., Hayashi, K., Itoh, K., et al. (2005). Extensive and orderly reprogramming of genome-wide chromatin modifications associated with specification and early development of germ cells in mice. Dev Biol, 278(2), 440-458.

Shah, M. Y., \& Licht, J. D. (2011). DNMT3A mutations in acute myeloid leukemia. Nat Genet, 43(4), 289-290.

Shen, L., Kondo, Y., Guo, Y., et al. (2007). Genome-wide profiling of DNA methylation reveals a class of normally methylated CpG island promoters. PLoS Genet, 3(10), 2023-2036.

Song, C. X., Szulwach, K. E., Fu, Y., et al. (2010). Selective chemical labeling reveals the genome-wide distribution of 5-hydroxymethylcytosine. Nat Biotechnol, 29(1), 68-72.

Straussman, R., Nejman, D., Roberts, D., et al. (2009). Developmental programming of CpG island methylation profiles in the human genome. Nat Struct Mol Biol, 16(5), 564571. 
Sunahori, K., Juang, Y. T., \& Tsokos, G. C. (2009). Methylation status of CpG islands flanking a cAMP response element motif on the protein phosphatase 2Ac alpha promoter determines CREB binding and activity. J Immunol, 182(3), 1500-1508.

Surani, M. A., Barton, S. C., \& Norris, M. L. (1984). Development of reconstituted mouse eggs suggests imprinting of the genome during gametogenesis. Nature, 308(5959), 548-550.

Szwagierczak, A., Bultmann, S., Schmidt, C. S., Spada, F., \& Leonhardt, H. (2010). Sensitive enzymatic quantification of 5-hydroxymethylcytosine in genomic DNA. Nucleic Acids Res, 38(19), e181.

Tahiliani, M., Koh, K. P., Shen, Y., et al. (2009). Conversion of 5-methylcytosine to 5hydroxymethylcytosine in mammalian DNA by MLL partner TET1. Science, 324(5929), 930-935.

Takai, D., \& Jones, P. A. (2002). Comprehensive analysis of CpG islands in human chromosomes 21 and 22. Proc Natl Acad Sci U S A, 99(6), 3740-3745.

Tang, L. Y., Reddy, M. N., Rasheva, V., et al. (2003). The eukaryotic DNMT2 genes encode a new class of cytosine-5 DNA methyltransferases. J Biol Chem, 278(36), 33613-33616.

Valinluck, V., \& Sowers, L. C. (2007). Endogenous cytosine damage products alter the site selectivity of human DNA maintenance methyltransferase DNMT1. Cancer Res, 67(3), 946-950.

Valinluck, V., Tsai, H. H., Rogstad, D. K., et al. (2004). Oxidative damage to methyl-CpG sequences inhibits the binding of the methyl-CpG binding domain (MBD) of methyl-CpG binding protein 2 (MeCP2). Nucleic Acids Res, 32(14), 4100-4108.

Van den Wyngaert, I., Sprengel, J., Kass, S. U., \& Luyten, W. H. (1998). Cloning and analysis of a novel human putative DNA methyltransferase. FEBS Lett, 426(2), 283-289.

Watanabe, D., Suetake, I., Tada, T., \& Tajima, S. (2002). Stage- and cell-specific expression of Dnmt3a and Dnmt3b during embryogenesis. Mech Dev, 118(1-2), 187-190.

Waterland, R. A., Dolinoy, D. C., Lin, J. R., et al. (2006). Maternal methyl supplements increase offspring DNA methylation at Axin Fused. Genesis, 44(9), 401-406.

Waterland, R. A., \& Jirtle, R. L. (2003). Transposable elements: targets for early nutritional effects on epigenetic gene regulation. Mol Cell Biol, 23(15), 5293-5300.

Waterland, R. A., \& Michels, K. B. (2007). Epigenetic epidemiology of the developmental origins hypothesis. Annu Rev Nutr, 27, 363-388.

Weaver, J. R., Susiarjo, M., \& Bartolomei, M. S. (2009). Imprinting and epigenetic changes in the early embryo. Mamm Genome, 20(9-10), 532-543.

Weber, M., Hellmann, I., Stadler, M. B., et al. (2007). Distribution, silencing potential and evolutionary impact of promoter DNA methylation in the human genome. Nat Genet, 39(4), 457-466.

White, G. P., Watt, P. M., Holt, B. J., \& Holt, P. G. (2002). Differential patterns of methylation of the IFN-gamma promoter at $\mathrm{CpG}$ and non-CpG sites underlie differences in IFNgamma gene expression between human neonatal and adult CD45RO- T cells. J Immunol, 168(6), 2820-2827.

Williams, K., Christensen, J., Pedersen, M. T., et al. (2011). TET1 and hydroxymethylcytosine in transcription and DNA methylation fidelity. Nature, 473(7347), 343-348.

Wossidlo, M., Nakamura, T., Lepikhov, K., et al. (2011). 5-Hydroxymethylcytosine in the mammalian zygote is linked with epigenetic reprogramming. Nat Commun, 2, 241. 
Wu, J. C., \& Santi, D. V. (1985). On the mechanism and inhibition of DNA cytosine methyltransferases. Prog Clin Biol Res, 198, 119-129.

Wu, J. C., \& Santi, D. V. (1987). Kinetic and catalytic mechanism of HhaI methyltransferase. J Biol Chem, 262(10), 4778-4786.

Wu, S. C., \& Zhang, Y. (2010). Active DNA demethylation: many roads lead to Rome. Nat Rev Mol Cell Biol, 11(9), 607-620.

Wu, Y., Strawn, E., Basir, Z., Halverson, G., \& Guo, S. W. (2006). Promoter hypermethylation of progesterone receptor isoform B (PR-B) in endometriosis. Epigenetics, 1(2), 106111.

Xie, S., Wang, Z., Okano, M., et al. (1999). Cloning, expression and chromosome locations of the human DNMT3 gene family. Gene, 236(1), 87-95.

Yoder, J. A., \& Bestor, T. H. (1998). A candidate mammalian DNA methyltransferase related to pmt1p of fission yeast. Hum Mol Genet, 7(2), 279-284.

Yoder, J. A., Soman, N. S., Verdine, G. L., \& Bestor, T. H. (1997). DNA (cytosine-5)methyltransferases in mouse cells and tissues. Studies with a mechanism-based probe. J Mol Biol, 270(3), 385-395.

Yoo, J., \& Medina-Franco, J. L. (2011). Trimethylaurintricarboxylic acid inhibits human DNA methyltransferase 1: insights from enzymatic and molecular modeling studies. J Mol Model.

Yu, Z., Genest, P. A., ter Riet, B., et al. (2007). The protein that binds to DNA base J in trypanosomatids has features of a thymidine hydroxylase. Nucleic Acids Res, 35(7), 2107-2115.

Yuen, R. K., Jiang, R., Penaherrera, M. S., McFadden, D. E., \& Robinson, W. P. (2011). Genome-wide mapping of imprinted differentially methylated regions by DNA methylation profiling of human placentas from triploidies. Epigenetics Chromatin, $4(1), 10$.

Yuen, R. K. C., Neumann, S. M. A., Fok, A. K., et al. (2011). Extensive epigenetic reprogramming in human somatic tissues between fetus and adult. Epigenetics and Chromatin, 4(7).

Zhu, B., Zheng, Y., Angliker, H., et al. (2000). 5-Methylcytosine DNA glycosylase activity is also present in the human MBD4 (G/T mismatch glycosylase) and in a related avian sequence. Nucleic Acids Res, 28(21), 4157-4165.

Zhu, B., Zheng, Y., Hess, D., et al. (2000). 5-methylcytosine-DNA glycosylase activity is present in a cloned G/T mismatch DNA glycosylase associated with the chicken embryo DNA demethylation complex. Proc Natl Acad Sci U S A, 97(10), 5135-5139.

Zhu, J. K. (2009). Active DNA demethylation mediated by DNA glycosylases. Annu Rev Genet, 43, 143-166.

Zimmermann, C., Guhl, E., \& Graessmann, A. (1997). Mouse DNA methyltransferase (MTase) deletion mutants that retain the catalytic domain display neither de novo nor maintenance methylation activity in vivo. Biol Chem, 378(5), 393-405.

Zucker, K. E., Riggs, A. D., \& Smith, S. S. (1985). Purification of human DNA (cytosine-5-)methyltransferase. J Cell Biochem, 29(4), 337-349. 


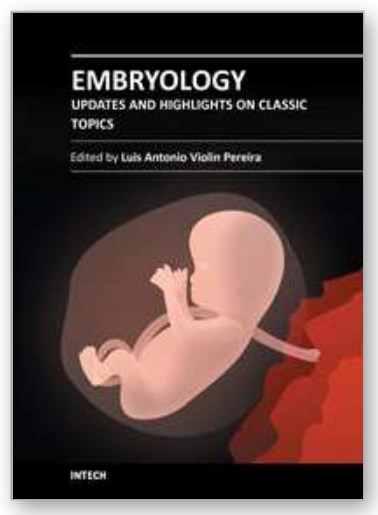

\author{
Embryology - Updates and Highlights on Classic Topics \\ Edited by Prof. Luis Violin Pereira
}

ISBN 978-953-51-0465-0

Hard cover, 222 pages

Publisher InTech

Published online 30, March, 2012

Published in print edition March, 2012

Embryology is a branch of science concerned with the morphological aspects of organismal development. The genomic and molecular revolution of the second half of the 20th century, together with the classic descriptive aspects of this science have allowed greater integration in our understanding of many developmental events. Through such integration, modern embryology seeks to provide practical knowledge that can be applied to assisted reproduction, stem cell therapy, birth defects, fetal surgery and other fields. This book focuses on human embryology and aims to provide an up-to-date source of information on a variety of selected topics. The book consists of nine chapters organized into three sections, namely: 1) gametes and infertility, 2) implantation, placentation and early development, and 3) perspectives in embryology. The contents of this book should be of interest to biology and medical students, clinical embryologists, laboratory researchers, obstetricians and urologists, developmental biologists, molecular geneticists and anyone who wishes to know more about recent advances in human development.

\title{
How to reference
}

In order to correctly reference this scholarly work, feel free to copy and paste the following:

Xin Pan, Roger Smith and Tamas Zakar (2012). DNA Methylation in Development, Embryology - Updates and Highlights on Classic Topics, Prof. Luis Violin Pereira (Ed.), ISBN: 978-953-51-0465-0, InTech, Available from: http://www.intechopen.com/books/embryology-updates-and-highlights-on-classic-topics/dna-methylation-indevelopment

\section{INTECH}

open science | open minds

\section{InTech Europe}

University Campus STeP Ri

Slavka Krautzeka 83/A

51000 Rijeka, Croatia

Phone: +385 (51) 770447

Fax: +385 (51) 686166

www.intechopen.com

\section{InTech China}

Unit 405, Office Block, Hotel Equatorial Shanghai

No.65, Yan An Road (West), Shanghai, 200040, China

中国上海市延安西路65号上海国际贵都大饭店办公楼405单元

Phone: +86-21-62489820

Fax: $+86-21-62489821$ 
(C) 2012 The Author(s). Licensee IntechOpen. This is an open access article distributed under the terms of the Creative Commons Attribution 3.0 License, which permits unrestricted use, distribution, and reproduction in any medium, provided the original work is properly cited. 